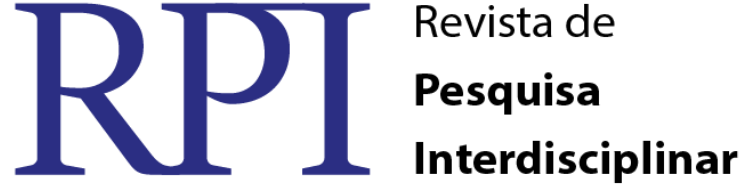

\section{UM BOM CAFÉ: DO BULE AO PALADAR!}

\author{
Juliano de Sousa Bezerra ${ }^{1}$ \\ Rosa das Neves Pereira ${ }^{2}$ \\ Gustavo de Alencar Figueiredo ${ }^{3}$
}

Resumo: Este trabalho pretendeu investigar a evolução dos/as estudantes durante a execução de uma Ilha Interdisciplinar de Racionalidade (IIR) desenvolvida no Componente Curricular de Física junto a estudantes da $2^{\text {a }}$ Série do Ensino Médio de uma Escola da Rede Pública de Cajazeiras - PB. A experiência foi realizada no decorrer do Estágio Supervisionado III, disciplina vinculada ao Curso de Física - Licenciatura da Universidade Federal de Campina Grande - PB, Campus de Cajazeira- PB. Para tanto, inicialmente, foi aplicado um questionário semiestruturado com questões que apresentam situações-problema acerca de conceitos centrais da Termodinâmica, tais como calor e temperatura, objetivando, dessa forma, identificar o quanto os/as estudantes, naquele instante, conseguiriam explicar tais situações à luz de suas construções intelectuais. O tema gerador escolhido para aplicação da metodologia das IIR foi escolhido pelo Professor-estagiário e situou a seguinte ponto: "um bom café"; todas as discussões foram propostas pelos/as estudantes e estavam de alguma forma ligada a temática. Ao término do estágio pedimos que fosse novamente respondido o questionário inicial e, assim, fizemos uma análise dos resultados da referida prática que foram apresentados por meio de tabelas, onde pôde-se verificar como eles/elas responderam às questões antes e depois de nossa intervenção em sala de aula. Verificou-se uma evolução dos/as estudantes com aplicação da Metodologia das Ilhas de Racionalidade Interdisciplinares, pois eles/elas apresentaram uma participação significativa durante à sua execução. Observou-se, também, que os/as estudantes tiveram dificuldades para compreender a construção da IIR, pois essa perspectiva, representa uma inovação metodológica para o Ensino de Física, sendo, portanto, distante do Ensino Tradicional e matematizado da Física em nível Médio percebido atualmente nas escolas.

Palavras-chave: IIR; Ensino de Física, Ensino Médio.

\section{A GOOD COFFEE: FROM MACHINE TO TASTE!}

\section{ABSTRACT}

\begin{abstract}
This study aimed to investigate the evolution of the students during the execution of an interdisciplinary island of rationality (IIR) developed in the Curriculum in Physics with students of the 2nd High School Series of Public School located in Cajazeiras city - PB. The experiment was conducted during the course of the curricular component of Supervised Practice in Physics degree from the Universidade Federal de Campina Grande, Cajazeiras Campus - PB. Initially, it was applied a structured questionnaire with questions that present situations-problem about core concepts of Thermodynamics, such as heat and temperature, aiming to identify how the students would explain such situations in the light of their intellectuals constructions. The theme "A Good Coffee" was chosen by the author and all discussions were proposed by the high school students and linked to theme somehow. At the end of the event, the same questionnaire was applied again and the analyses of the results were presented in tables, where it is possible to compare the answers before and after the
\end{abstract}

\footnotetext{
1) UFCG - CFP,soujulianosousa@ gmail.com

${ }^{2}$ UFCG - CFP,rosadasnevesp2@gmail.com

${ }^{3}$ UFCG - CFP - UACEN, gualfig@ufcg.edu.br
} 
intervention in the classroom. The results indicate an increase of students when applying the interdisciplinary island of rationality methodology since they had a significant participation in its execution. It was also noted that students had difficulty understanding the construction of the IIR because this perspective is a methodological innovation for Physical Education and far from Traditional and mathematized Physics Education in high school.

Keywords: IIR; Physical Education, High School.

\section{Colocando água para ferver}

Durante o decorrer do curso de Física (Lic), na Universidade Federal de Campina Grande (UFCG), pudemos ter o contato com críticas ao Ensino de Física e durante esses estudos chegamos à conclusão de que ele, em sua maioria, não trás discussões relevantes para a formação de uma visão crítica de mundo, sendo por isso de extrema importância a procura por novos métodos de ensino. Em nosso Estágio Supervisionado III, tivemos o contato com as ideias de Gerard Fourez, que versava sobre as Ilhas Interdisciplinar de Racionalidade (IIR).

Como mostra o trabalho de Alves 2004, essas concepções levam a uma proposta nova e não muito conhecida, principalmente, em nossa região, onde há poucos trabalhos escritos sobre esse tema e, por isso, devemos dar a essa metodologia uma atenção especial. Durante o estágio supervisionado Procuramos realizar o estudo do desenvolvimento de estudantes, que tiveram contato com esta forma de ensino, nos estudos relacionados à termometria, em nosso Estágio procuramos invertigar como a metodologia das Ilhas Interdisciplinar de Racionalidade (IIR) de Gerard Fourez contribuem para o ensino da Física, particularmente no ensino dos conceitos relacionados à termometria.

\section{Coando o café}

Para que um estudante tenha empenho em resolver um problema, este deve ser tido como próprio por ele(a) de acordo com Pozo 1998 e Nehring et al 2000, muitas vezes os que apresentamos para os/as estudantes em sala de aula, são distantes da realidade que eles encontram fora das salas de aula. Tudo isso contribui para o insucesso dos projetos de ensino, que não levam a aproximação entre conceitos científicos e realidade dos estudantes em consideração. Essa dicotomia entre conhecimento escolar e conhecimento do cotidiano coloca 
o conhecimento escolar como uma coisa que pertence somente ao interior dos muros da escola.

Esse afastamento, também contribui para a crença por parte dos estudantes de que a ciência é uma verdade absoluta e que não pode ser questionada, além de ser "descoberta" pelos cientistas e como podemos ver em vários autores de história e filosofia da ciência estes dois modos de ver a ciência são equivocados.

Sobre essa situação Pietrocola diz:

Muito pouca coisa tem sido feita para que os alunos percebam que o conhecimento científico aprendido na escola serve como forma de interpretação do mundo que o cerca. (...) não parece que os alunos percebem que as teorias científicas permitem de construir explicações engenhosas sobre os fenômenos que eles presenciam no dia-a-dia. (...) acredito que se deve re-inserir com urgência a realidade como objeto da educação científica. Não nos moldes determinados pelo empiricismo ingênuo, mas enfatizando o conhecimento construído pela ciência como esboço da realidade. (...) a realidade passa a ser o objetivo final da educação científica, que deve, porém ser perseguida pela construção de modelos.(PIETROCOLA, 1998, p. 7).

Uma das formas de se reintroduzir a realidade no Ensino de Ciências, de Física em especial, é seguindo a ideia de Fourez, segundo ele, um dos meios de se reintroduzir a realidade no ensino é uma forma de abordagem dos conceitos científicos, que gira em torno de um problema real, essa abordagem é conhecida como Ilhas Interdisciplinar de Racionalidade (IIR). Nesta forma de abordagem além de inferirmos os estudos sobre um problema real, fazemos também o uso da interdisciplinaridade, uma vez que nesta forma de abordagem o planejamento é aberto e os estudantes são participantes ativos nas decisões nos rumos que a resolução do problema deve tomar, além disso, essa abordagem, também valoriza o que o/a estudante já sabe e como citado no quesito acima valorizar os conhecimentos que os estudantes trazem do cotidiano é uma forma de contribuir pra que o ambiente seja mais favorável à aprendizagem dos conceitos científicos.

Como discutido por Fourez 1995, uma IIR visa produzir uma representação teórica apropriada em uma situação precisa e em função de um projeto determinado, desta forma, podemos trabalhar os conceitos científicos em cima de uma situação mais próxima do cotidiano, assim os/as estudantes desenvolvem habilidades que serão usadas em seu cotidiano 
quando saírem da sala de aula. Fourez destaca essas habilidades fora da sala de aula como sendo Autonomia, Comunicação e Domínio.

Dessa forma os/as estudantes teriam a capacidade de negociar na resolução de seus problemas cotidianos fora da escola.

Na descrição de IRI segundo Nehring et al 2000

Ao se construir uma ilha de racionalidade surgirão questões específicas ligadas a determinado conhecimento científico que poderão ser respondidas ou não conforme o caso. Estas questões abertas são denominadas de caixaspretas. O contexto e os objetos do projeto orientam a abertura ou não das caixas-pretas. Uma caixa-preta aberta significa a obtenção de modelos que possam relacionar os fatos conhecidos, gerando explicações. Nesse contexto, uma ilha de racionalidade ancora-se na construção de modelos, visando a solução de problemas de interesse a partir do cotidiano dos indivíduos. (NEHRING et al, 2000, p.06).

Abordando os conceitos científicos desse jeito apresentaríamos os conceitos científicos para os alunos de uma forma mais humana, ou seja, de uma maneira que os alunos possam compreender o conhecimento científico como sendo criado pela humanidade para resolver problemas que inquietaram cientistas e que estes criaram modelos que se aproximam da realidade para explicar essa situações, como diz Nehring et al 2000 ao falar das IIRs:

Nesse sentido, a Alfabetização Científica e Técnica imporia uma nova sistemática na transposição didática, sendo os diversos saberes, introduzidos em sala de aula, fruto de seleção e ponderação e determinados pelo contexto do problema a ser resolvido. O conhecimento disciplinar, contido na dimensão do saber sábio, perderia definitivamente sua aura de verdade geral, em favor de um saber legitimado pelo seu potencial explicativo local e pela capacidade de gerar soluções práticas. (NEHRING et al, 2000, p. 08)

Sendo assim para vários autores, entre eles os acima citados, as IRIs proporcionam uma boa abordagem de conceitos científicos para contribuir para a autonomia dos estudantes e uma alfabetização cientifica mais humana.

\section{Metodologia}

RPI Revista de Pesquisa Interdisciplinar, Cajazeiras, v. 1, Ed. Especial, 479 - 487, set/dez. de 2016. 
Nesta pesquisa se pretende avaliar o quanto estudantes evoluirão durante o decorrer da execução de uma IIR, para isso, se aplicará um questionário inicial a respeito dos conhecimentos científicos que estarão por ser estudados. O objetivo de tal questionário e identificar o quanto, naquele momento, os estudantes conseguem explicar com os conhecimentos que tem termometria.

Depois deste questionário os pesquisadores irão construir e executar uma IIR junto com os/as estudantes, para tal, se seguirá os passos de construção e execução sugeridos e comentados por Nehring e Alves, tomando o devido cuidado com o tempo para a execução da pesquisa. No final de tal etapa, será aplicado outro questionário e os resultados dos estudantes serão comparados com as do primeiro, para que assim, se tenha dados sobre o quanto os estudantes conseguiram "evoluir" na capacidade de resolução de situações envolvendo o referido conteúdo. É necessário dizer aqui que o questionário aplicado será o mesmo nas duas situações, porém, uma IRI é uma métodologia de abordagem que tem como uma das principais características a participação dos estudantes, tanto na sua construção como também em sua execução, por tanto, a nosso ver não é justo que a análise dos resultados leve em consideração apenas comparações quantitativas dos estudantes, essa metodologia deixaria de privilegiar as interações entre as pessoas que estão participando de tal ação, desde modo, se faz necessário também à análise de tal trabalho a partir de um olhar que levem em consideração essas interações (Oliveira 2008). Dessa forma, se fará um relato das interações estre professor e estudante a fim de relatar como as relações estre estes sujeitos se dá durante a metodologia.

Para alcançar tais comparações será escolhida uma turma de uma escola pública da cidade de Cajazeiras-PB, e o tema da IIR escolhi foi um bom café, uma vez que esse ema atendia as nossa necessidades de se trabalhar assuntos ligados a termometria para a realização deste projeto serão dados os seguintes passos para a criação da IIR:

Fazer um clichê da situação estudada: essa etapa é o ponto de partida dos trabalhos, o grupo de estudantes ao qual o tema foi apresentado formula diversas questões (caixas pretas) ao seu respeito, estas perguntas podem ter caratér científico ou não, podem ser levados em consideração conhecimento do cotidiano. Panaroma espontâneo: nesta etapa as questões levatadas no clichê são analisadas pelo professor e pelos/as estudantes, a fim de ver se a necessidade de aprofundamento das questões ou se algum aspecto do tema, que deseja-se ser estudado foi deixado de fora. Indo à prática: nesta etapa, deixamos de pensar sobre a situação para confrontá-la com a prática. Abrindo algumas caixas pretas sem a ajuda de RPI Revista de Pesquisa Interdisciplinar, Cajazeiras, v. 1, Ed. Especial, 479 - 487, set/dez. de 2016. 
especialistas: todos nós temos uma representação teórica sobre os assuntos, podemos utilizar esta representação para realizar a abeerura de algumas caixas pretas sem a ajuda de especialistas.Consulta a especialistas: nesta etapa os/as estudantes podem apreder como e quando devem consultar especialistas na sua vida cotidiana. Abertura de caixas pretas: nesta etapa, como o próprio nome diz, ocorre à abertura das caixas pretas, este passo deve ser feito de acordo com o projeto. Esquematização global: nesta estapa se faz uma sítese do objeto da IIR, o objetivo aqui é fazer uma representação teórica da situação. Sítese da IIR produzida: nesta etapa é apresentado o resultado final da IIR, pode ser feito por meio da apresentação de um relatótio final.

Não há uma sequência definitiva para os passos que serão tomados durante a execusã da IIR, esses passos foram organizados de acordo com a visão destes autores, mas ela pode ser diferente dependendo da necessidade que surja na execussão da IIR. Dessa forma, pretende-se fazer com que os/as estudantes participem de forma ativa da construção do conhecimento e o/a professor/a atue como um organizador desse trabalho.

\section{O café na xícara}

Para analisar os resultados, optamos por separar as questões em três categorias da seguinte forma: as questões 1, 7 e 8 foram alocadas na categoria transferência de energia interna, tendo em vista que elas, de alguma forma, exigem que o/a estudante tenha o conhecimento de como a energia interna é transferida, as questões 2, 4 e 5 foram locadas na categoria dilatação dos sólidos, e a questão 3 foi englobada na categoria mudança de fase.

Como podemos ver na tabela 01 abaixo grande parte dos estudantes não tinham, antes de começarmos os estudos, conhecimento de como a energia interna era transferida de um corpo para outro, em suas respostas os/as estudantes deixavam transparecer que não associavam o conceito de temperatura à agitação das partículas, como por exemplo, na questão de número 7 uma grande parte das respostas afirmavam não haver um limite mínimo para a temperatura de um corpo, também demostraram não ter conhecimento de como essa energia era transferida de um corpo para outro, como por exemplo, uma parte considerável das respostas para a questão de número 8 afirmavam que o termômetro deveria passar um tempo em contato com o corpo da pessoa para que ele absorvesse a temperatura do corpo. Quanto à segunda categoria, dilatação dos sólidos, podemos ver algo semelhante, nem um/a RPI Revista de Pesquisa Interdisciplinar, Cajazeiras, v. 1, Ed. Especial, 479 - 487, set/dez. de 2016. 
estudante conseguiu dar uma resposta satisfatória para a questão de número 4, na maioria das respostas deixava-se transparecer que eles/as não tinham o conhecimento de que os sólidos dilatavam-se quando submetidos a uma variação de temperatura a mesma coisa podia se vista nas respostas da questão de número 5, na última categoria a maioria dos/as estudantes também deram respostas insatisfatórias, e maioria das respostas associaram a secagem das roupas ao vento, alternativa $b$.

\section{TABELA 01 - RESPOSTAS DE QUESTIONÁRIO ANTES DA METODOLOGIA}

\begin{tabular}{cccc}
\hline Questão & $\mathrm{N}^{\mathbf{0}}$ de respostas satisfatórias & $\mathrm{N}^{\mathbf{0}}$ de respostas insatisfatórias & Não soube responder \\
$\mathbf{1}$ & 27 & 17 & 0 \\
$\mathbf{2}$ & 13 & 29 & 1 \\
$\mathbf{3}$ & 12 & 31 & 9 \\
$\mathbf{4}$ & 0 & 35 & 17 \\
$\mathbf{5}$ & 4 & 23 & 8 \\
$\mathbf{6}$ & 2 & 34 & 10 \\
$\mathbf{7}$ & 2 & 32 & 1 \\
\hline
\end{tabular}

Quando os/as estudantes começaram a abrir as caixas pretas logo se mostraram envolvidos e participativos. Acreditamos baseando-nos em Pozo (1998), que isto tenha acontecido por que os/as estudantes perceberam estes problemas como seus, pois segundo o autor citado, eles/elas se mostram apáticos quando não percebem que aquele problema pode ter uma relação com o seu cotidiano; ao contrário, se eles/as percebem isso, tomam o problema como sendo seu e se envolvem na sua resolução. Nesta aula, tivemos uma boa participação dos/as estudantes que assistiam a apresentação de seus colegas. Porém, durante a execução do projeto, encontramos, certa resistência dos/as estudantes a essa nova metodologia, quando mostrei as funções de dilatação houve uma preocupação generalizada. Sempre havia interrupção com perguntas do tipo: "essas contas aí vão cair na prova?" ou "professor o senhor cobra mais conta ou mais teoria?" também "se a pessoa acertar a metade da conta o senhor vai considerar?" Por muitas vezes tivemos que mudar o decorrer da aula para fazer comentários sobre essas perguntas.

RPI Revista de Pesquisa Interdisciplinar, Cajazeiras, v. 1, Ed. Especial, 479 - 487, set/dez. de 2016. 
Isso mostra como os/as estudantes notam a escolarização como uma forma de conseguir boas notas nas avaliações. Nessas atitudes os/as estudantes deixaram transparecer o modo como a educação é encarada. Podemos entender em, seus comentários, que eles/as tiveram poucos contatos com a exposição de conteúdos de uma forma preocupada com a sua formação para a vivência em sociedade. Com isso, podemos nos fazer algumas perguntas tais como: onde e quando os professores estão preocupados com uma educação da forma como criticada por Paulo Freire (uma educação voltada para a formação de um cidadão que possa compreender o mundo a sua volta e ser ativo perante esse)? Onde os/as educandos/as podem enxergar o conhecimento como algo que pode utilizar para explicar acontecimentos do seu cotidiano?

Na tabela 02, está descrito o resultado obtido na resolução do questionário por parte dos/as estudantes, nela podemos ver que houve um considerável avanço no número de respostas consideradas satisfatórias para as categorias citadas acima. A diferença no número de estudantes que participaram da primeira estapa (primeira tabela) e da última etapa (segunda tabela) se deve ao fato de que o primeiro questonário foi aplicado nos primeiros dias do ano letivo e, por isso, alguns dos/as estudantes ainda não estavam frequantando a escola. $\mathrm{Na}$ segunda aplicação estavamos já na segunda metade do primeiro bimestre e todos/as estudantes já estavam frequantando as aulas.

\section{TABELA 02 - RESPOSTA DE QUESTIONÁRIO DEPOIS DA METODOLOGIA}

\begin{tabular}{|c|c|c|c|}
\hline Questão & $\begin{array}{c}\mathrm{N}^{\mathrm{o}} \text { de respostas } \\
\text { satisfatórias }\end{array}$ & $\begin{array}{l}\mathrm{N}^{\mathrm{o}} \text { de respostas } \\
\text { insatisfatórias }\end{array}$ & Não soube responder \\
\hline 1 & 44 & 6 & 0 \\
\hline 2 & 45 & 5 & 0 \\
\hline 3 & 7 & 43 & 0 \\
\hline 4 & 23 & 25 & 2 \\
\hline 5 & 46 & 4 & 2 \\
\hline 6 & 24 & 23 & 3 \\
\hline 7 & 37 & 12 & 1 \\
\hline 8 & 43 & 7 & 0 \\
\hline
\end{tabular}

RPI Revista de Pesquisa Interdisciplinar, Cajazeiras, v. 1, Ed. Especial, 479 - 487, set/dez. de 2016. 
Esse avanço na resolução de questões pode ser atribuido ao fato dos/as estudantes terem participado ativamente da metodologia, como pode ser visto nos/as autores/as citados acima, uma participação ativa na construção de conhecimeto é fundamental para o desenvolvimento no que diz respeito a aprendizagem significativa dos conceitos da Física.

\section{Concluindo os resultados}

Analisando e comparando os resultados, podemos considerar a IIR como uma boa metodologia para ajudar os/as estudantes na construção dos conhecimentos científicos uma vez que é notável avanço tanto na resolução de questões sobre esses conceitos como na interação entre professor e estudante, porém na sua aplicação encontramos algumas resistências, como por exemplo, por várias vezes fomos questionados por que estávamos realizando estudos a respeito do café e não estudos relacionados à Física, também fomos questionados, como citado acima, sobre o fato de não utilizarmos tantas funções. Isso demostra o quanto os/as nossos/as estudantes estão acostumados a lidar com um ensino tradicional.

\section{REFERÊNCIAS}

ALVES, Jose de Pinho. Desafio docente: As ilhas de racionalidade e seus elementos interdisciplinares. Florianópolis. 2004.

FREIRE, Paulo. Educação como prática da liberdade. Editora Paz e Terra. Rio de JaneiraRJ. 1967.

FOUREZ, G. A construção das ciências: INTRODUÇÃO à filosofia e à ética das ciências. São Paulo: UNESP, 1995.

NEHRING, Cátia Maria, et al. As ilhas de racionalidade e o saber significativo: o ensino de ciências através de projetos Ensaio pesquisa em educação ciências. Volume II. Minas Gerais. 2000 .

Pietrocola, M. Modelos e realidade no conhecimento científico; limites da abordagem construtivista processual, Atas eletrônicas do VI Encontro de Pesquisa em Ensino de Física, outubro de 1998, Florianópolis, Santa Catarina.

POZO, Juan Ignacio (org). A solução de problemas: Aprender a resolver para aprender. Editora: ArtMed. Porto Alegre 1998.

RPI Revista de Pesquisa Interdisciplinar, Cajazeiras, v. 1, Ed. Especial, 479 - 487, set/dez. de 2016. 